\title{
Tecnologia da Informação em Pequenas Empresas: Fatores de Êxito, Restrições e Benefícios
}

\author{
Glaúcia Aparecida Prates \\ Marco Túlio Ospina
}

\begin{abstract}
Resumo
Existem poucos estudos sobre análises do desempenho da Tecnologia da Informação em pequenas empresas, principalmente em países em desenvolvimento como o Brasil. O artigo propõe-se a analisar os impactos que a Tecnologia da Informação provocou nos aspectos organizacionais, referentes aos critérios de desempenho nas empresas analisadas, além de identificar a sua amplitude de uso, os fatores que contribuem para o seu êxito, os motivos que levaram ao seu uso e as dificuldades encontradas na sua implantação. Consideraram-se fatores como os seguintes: a) aumento da continuidade; b) melhoria dos controles; c) condições de proporcionar maior compreensão das funções produtivas. A pesquisa foi realizada por meio de um estudo multicaso em 25 empresas, no primeiro trimestre de 2002, que atuam nos setores eletro-eletrônico, distribuição e comércio e serviços. Os resultados indicaram que a implantação da Tecnologia da Informação (TI) trouxe como maiores fatores de êxito, apontados pelas empresas, os dois seguintes: a percepção da necessidade pelos usuários e o apoio da cúpula administrativa. Como benefícios foram destacados esta dupla: melhoria na compreensão produtiva, aumento na satisfação do usuário.
\end{abstract}

Palavras-chaves: tecnologias da informação; pequenas empresas; impacto organizacional.

\begin{abstract}
Studies have been conducted on Information Technology in specific areas, about standards and success factors, user's satisfaction. There are a few papers about IT (Information Technology) analysis in small business, mainly in countries under development such as Brazil. The aim of this paper is to describe the organizational impact due to the IT implementation in small business, considering performance criterion, success factors, adoption motivation and difficulties. IT considers three factors such as: a) to increase the continuity; b) controls more efficient; c) to provide more understanding of productive functions. This research was conducted by multicases method in 25 firms, during the first trimester of 2002. The studied firms integrate many sectors such as electrical-eletronical, logistic, commerce and services. The results indicated the two highest scores on success factors: use needs perceptions and management support. As benefits were pointed: a better understanding of productive functions and user's satisfaction.
\end{abstract}

Key words: information technology; small business; organizational impact. 


\section{INTRODUÇÃO}

Estima-se que o uso de computadores em pequenas empresas ao longo dos últimos 5 anos, cresceu 30-80\%, dependendo da localização e natureza do negócio (Palvia \& Palvia, 1999).

Entretanto tal estatística indica que o aumento do uso ocorre principalmente nas funções operacionais e administrativas e não em atividades estratégicas e de tomada de decisões (Fuller, 1996).

Pesquisas já realizadas em TI (Tecnologia da Informação) em áreas especificas, padrões de uso da informática, fatores de êxito, percepção de uso da TI. Fuller (1996) também fornece ampla análise das questões de TI nas pequenas empresas.

Entretanto pouca literatura foi encontrada relativa à análise da TI em pequenas empresas, principalmente em países em desenvolvimento, como é o caso do Brasil.

O objetivo deste artigo é descrever o impacto organizacional derivado da implantação de Tecnologia da Informação em pequenas empresas considerando as indicações de Zuboff (1994). Consideram-se fatores como os três seguintes: a) aumento da continuidade; b) melhoria dos controles; c) aumento da compreensão das funções produtivas.

\section{Importância da TI nas Organizações}

Não há mais dúvidas de que para as funções da administração - planejamento, organização, liderança e controle - são de suma importância os sistemas que fornecem informações aos administradores. Para Stoner (1999) somente com informações precisas e na hora certa os administradores podem monitorar o progresso na direção de seus objetivos e transformar os planos em realidade.

Assim, para esse autor as informações devem ser avaliadas segundo quatro fatores:

- qualidade da informação - quanto mais precisa a informação, maior sua qualidade e com mais segurança os administradores podem contar com ela no momento de tomar decisões; 
. oportunidade da informação - para um controle eficaz, a ação corretiva deve ser aplicada antes de ocorrer um desvio muito grande do plano ou do padrão; portanto as informações devem estar disponíveis para a pessoa certa no momento certo;

. quantidade da informação - dificilmente os administradores podem tomar decisões precisas e oportunas sem informações suficientes; contudo é importante que não haja uma inundação de informações, de modo a esconder as coisas importantes;

. relevância da informação - de modo semelhante, a informação que os administradores recebem deve ter relevância para suas responsabilidades e tarefas (Stoner, 1999).

O propósito básico da informação, dentro do contexto organizacional, de acordo com Oliveira (1998), é o de habilitar a empresa a alcançar seus objetivos por meio do uso eficiente dos recursos disponíveis (pessoas, materiais, equipamentos, tecnologia, dinheiro, além da própria informação). Neste sentido, a teoria da informação considera os problemas e as adequações do seu uso efetivo pelos tomadores de decisão.

Segundo Oliveira (1998), a eficiência na utilização da informação é medida em relação ao custo para obtê-la e o valor do benefício derivado de seu uso. Associamse à produção da informação os custos envolvidos na coleta, processamento e distribuição.

Chaves \& Falsarella (1995) afirmam que há relação entre as características dos sistemas de informação e os estágios de desenvolvimento da Informática em que uma organização se encontra, conforme propõe Nolan (1977), o que vem descrito no Quadro 1 a seguir. 


\section{Quadro 1: Estágios da Tecnologia da Informação nas Organizações}

\begin{tabular}{|c|c|c|}
\hline Estágio & Caracteristicas & Sistemas \\
\hline Iniciaçäo & $\begin{array}{l}\text { Automaçāo de processos manuais } \\
\text { Inexiste planejamento } \\
\text { Inexiste participaçäo do usuário }\end{array}$ & $\begin{array}{l}100 \% \text { dos sistemas são } \\
\text { para controles opera- } \\
\text { cionais (Transacionais) }\end{array}$ \\
\hline Contágio & $\begin{array}{l}\text { Proliferação de aplicaçöes } \\
\text { Inexiste planejamento } \\
\text { Fraca participação do usuário } \\
\text { Reestruturaçäo interna do CPD }\end{array}$ & $\begin{array}{l}\text { Pelo menos } 15 \% \text { dos } \\
\text { sistemas são para controle } \\
\text { gerencial }\end{array}$ \\
\hline Controle & $\begin{array}{l}\text { Início de controle dos recursos de Informática } \\
\text { Usuário responsabilizado (arbítrio) } \\
\text { Utilização de Banco de Dados }\end{array}$ & $\begin{array}{l}80 \% \text { - operacional } \\
20 \% \text { - gerencial }\end{array}$ \\
\hline Integraçào & $\begin{array}{l}\text { Controle e Contabilização do Proc. de Dados } \\
\text { Usuário participante e envolvido nos processos }\end{array}$ & $\begin{array}{l}65 \% \text { - operacional } \\
35 \% \text { - gerencial }\end{array}$ \\
\hline $\begin{array}{l}\text { Administra- } \\
\text { çäo de } \\
\text { Dados }\end{array}$ & $\begin{array}{l}\text { Organização e integração das aplicaçöes } \\
\text { Organização voltada para Adm. Corporativa } \\
\text { Usuário consciente do processo } \\
\text { Fluxo de informaçōes integrado }\end{array}$ & $\begin{array}{l}55 \% \text { - operacional } \\
45 \% \text { - gerencial } \\
\text { (executivos) }\end{array}$ \\
\hline Maturidade & $\begin{array}{l}\text { Planejamento da informação como recurso } \\
\text { Efetiva participação dos usuários }\end{array}$ & $\begin{array}{l}45 \% \text { - operacional } \\
55 \% \text { - gerencial }\end{array}$ \\
\hline
\end{tabular}

Fonte: Chaves e Falsarella (1995).

\section{A Pequena Empresa e o Uso da Tecnologia de Informação}

Conforme Solomon (1986), uma dada tecnologia não é automaticamente boa ou má para a pequena empresa. Seu resultado dependerá da maneira como esta tecnologia será aplicada. Na verdade, o aumento da precisão organizacional, auxiliada por sistemas de informação, trará maior eficiência na administração de seus processos, recursos e atividades e maior eficácia na obtenção de resultados previamente estabelecidos.

\section{Impacto da Tecnologia da Informação nas Organizações:}

Segundo Gonçalves (1993), a tecnologia é o fator individual de mudança de maior importância na transformação das empresas. Tais transformações não se restringem apenas ao modo de produzir bens e serviços, mas induzem novos processos e instrumentos que atingem por completo a estrutura e o comportamento das organizações, repercutindo diretamente em sua gestão. 
A relação entre estrutura organizacional e tecnologia tem sido alvo de grande atenção, uma vez que as recentes inovações trazem mudanças radicais nas organizações, já que são capazes de alterar a forma de administrar a empresa ou até mesmo o local de realização do trabalho (Gonçalves, 1993).

Certamente, se nada mudar em relação à maneira pela qual o trabalho é feito e se o papel da TI for meramente o de automatizar um processo já existente, as vantagens econômicas serão mínimas.

Os impactos sobre a produtividade e a forma geral de organização das empresas podem ser muito significativos, pois a TI é diferente de outras formas de tecnologia que afetam as tarefas de produção e coordenação, ou que expandem a memória organizacional (Oliveira, 1996). O impacto da tecnologia pode provocar a transformação no trabalho das pessoas, na produção dos grupos, no desenho da própria organização e no desempenho da empresa (Gonçalves, 1998).

De acordo com Yong (1992), nos países do primeiro mundo a TI tem sido considerada como um dos fatores responsáveis pelo sucesso das organizações, tanto no âmbito de sobrevivência, quanto no aumento da competitividade. Corroborando este pensamento, Zuboff (1994) afirma que a TI, baseada nos computadores, está proporcionando nova infra-estrutura para as várias atividades produtivas e comunicativas, algo vital para a vida organizacional.

Os administradores em geral investem em novas ferramentas de TI, porque acreditam que isso lhes permitirá realizar suas operações mais rapidamente e a um custo mais baixo; utilizam-na para objetivos estratégicos e para planejar e alcançar um ou mais dos três objetivos operacionais independentes:

a) aumentar a continuidade (integração funcional, automação intensificada, resposta rápida);

b) melhorar o controle (precisão, acuidade, previsibilidade, consistência, certeza);

c) proporcionar maior compreensão das funções produtivas (visibilidade, análise, síntese).

As atividades mais suscetíveis a alterações, segundo Oliveira (1996), são aquelas de intensiva informação, podendo-se distinguir três grupos:

- Produção. A física (crescentemente atingida pela robótica e instrumentação de controle), a produção de informação (influenciada pelos computadores em tarefas burocráticas, como contas a receber, contas a pagar, faturamento etc.) e a produção de conhecimento (CAD, CAM, análise de crédito e risco, produção de software etc.). 
. Trabalhos de coordenação. A telecomunicação é o instrumento fundamental da mudança. Afeta a distância física, a natureza do tempo sobre o trabalho, armazena informações e mantém a memória organizacional como banco de conhecimento.

- Gestão. Afeta a direção, ao permitir monitorar o ambiente e tomar as decisões para adaptar a organização ao ambiente; afeta o controle, ao medir o desempenho e compará-lo com os planos, para manter-se no rumo desejado.

\section{Custos com Tecnologia de Informação}

Para Giurliani (1999) o uso de tecnologias de informação carrega consigo custos 'invisíveis', que são aqueles referentes aos gastos com usuário final, como suporte e treinamento informais (quando alguém interrompe suas atividades para auxiliar um colega com dificuldades referentes ao uso ou obtenção da informação); perda de tempo em atividades extremamente elaboradas para obter uma informação, cujo valor não compensa o trabalho empregado; finalmente, custos decorrentes da perda de produtividade, devido à indisponibilidade da informação (queda do sistema, por exemplo).

Da mesma forma, para o autor os custos mais facilmente mensuráveis ('visíveis') seriam aqueles relacionados a hardware e software (despesas com compra e/ ou leasing de equipamentos, upgrades, atualizações); gerenciamento (redes, sistemas, banco de dados); suporte (helpdesk, treinamento, viagens, manutenção); desenvolvimento (aplicações, testes e documentação, customização e manutenção); e taxas de comunicação (aluguel de linhas de comunicação de dados, taxas de acesso a servidores).

\section{Pesquisas Realizadas sobre TI em Pequenas Empresas}

Segundo Thong (2001, p.148), “enquanto a literatura de Sistemas de Informação tem identificado fatores potenciais para o sucesso da implementação de TI, nenhuma pesquisa tem investigado a importância relativa destes fatores no contexto das pequenas empresas”.

O mesmo autor ainda cita que as pequenas empresas possuem inúmeras características diferentes das grandes e médias empresas; e notavelmente sofrem de recursos reduzidos. Sem conhecer a importância de fatores-chaves, as pequenas empresas podem estar gastando recursos limitados e energia em fatores de pouca importância para a contribuição limitada no sucesso da implementação da TI. Dessa maneira, Thong (2001) realizou uma pesquisa sobre as restrições 
de recursos e implementação de sistemas de informação em pequenas empresas em Singapura, baseada no modelo de implantação de TI em pequenas empresas de Welsh \& White (1981), o qual considerou a estrutura de restrições de recursos em pequenas empresas e a teoria das restrições de Attewell (1992). O modelo foi testado em amostra de 114 pequenas empresas. Os resultados comprovaram que as pequenas empresas com sucesso em TI tendiam a ter alta participação de especialistas externos, investimento adequado, alto conhecimento dos usuários, alto grau de envolvimento do usuário e alto suporte do gerente geral. Concluindo assim que tal participação do especialista externo é a chave principal do sucesso da implantação da TI em pequenas empresas.

Palvia e Palvia (1999) conduziram um estudo focalizado em empresas verdadeiramente pequenas, as quais possuíam um numero muito reduzido de funcionários e não possuíam um departamento de Gestão de Sistema de Informação formal.

Neste ambiente, o proprietário era também gerente, e principal usuário, além de desempenhar as principais atividades de TI. Dessa maneira os autores construíram um instrumento de medição da satisfação em TI. Uma pesquisa foi conduzida em amostra de 1460 empresas para identificar os padrões de satisfação. As áreas de insatisfação em TI foram: treinamento e educação, manutenção dos softwares, documentação e suporte pelo fabricante. Nessas áreas as deficiências foram devidas ao comportamento dos vendedores de software e consultores. Finalmente, a análise de contingência da satisfação em TI baseou-se em fatores relacionados ao negócio em si e às características dos proprietários. A observação concluiu que as características do proprietário têm impacto maior na satisfação em TI do que qualquer outro fator. No estudo esses autores consideraram gênero, idade do proprietário, raça e habilidade em computação.

Um novo ângulo de se avaliar a TI também tem sido estudado em países de pouco desenvolvimento. Anandajaran, Igbaria e Anakwe (2002) realizaram um estudo para determinar os fatores que motivam os usuários a aceitar a TI. Foram coletados dados de 143 usuários na Nigéria que apontaram a pressão social como importante fator.

Segundo El-Manaki (1990), a pequena empresa absorve novas tecnologias de informação de forma lenta e limitada nos seus processos administrativos ou de produção. De acordo com o autor uma das razões para que isto ocorra é a falta de tecnologia específica para a pequena empresa. O uso de ferramentas de apoio de decisão para a pequena empresa é fator diferencial. Esses sistemas, de acordo com Machado (1996), são itens de primeira necessidade para profissionais, cujas decisões definem os destinos de produtos e serviços e, em conseqüência, o êxito ou o fracasso das organizações. 
O panorama da pequena empresa no Brasil, sob o aspecto de tecnologias de informação, não é dos melhores. Uma pesquisa da Microsoft, citada por Silva (1997), indica que $58 \%$ das pequenas empresas que não possuem computadores acreditam que a informática seja desnecessária; 5\% nem sabem os motivos pelos quais não se automatizam; e 11\% afirmam estar providenciando a compra de computadores.

Estatísticas da Sondagem Sebrae (2000) mostram que apenas 30\% das micros e pequenas empresas estão totalmente informatizadas. Destas, 50\% não possuem acesso à Internet e 55\% não possuem computadores ligados em rede. Por meio desses números, verifica-se que existe informatização apenas de processos operacionais isolados da empresa. Desses sistemas de informação não se extraem informações relevantes para a tomada de decisão, nem do ambiente interno da empresa e muito menos do seu ambiente externo. Para Saviani (1995) a informática, nas pequenas empresas, não tem a mínima visão de como produzir informações, sejam elas gerenciais ou não.

Apesar deste cenário, uma parcela de pequenas empresas, impulsionadas pela competitividade (incluindo grandes empresas) está optando por informatizar seu negócio. Cerca de $80 \%$ das pequenas empresas informatizadas atribuem o grau de 'muito importante' ao uso de computadores na empresa.

\section{A Qualidade e a Necessidade da Tecnologia de Informação na Pequena Empresa}

Neste sentido, um sistema de informação, voltado à pequena empresa, deve respeitar alguns quesitos: custo, tempo e qualidade.

Silva (1997) afirma que as pequenas empresas brasileiras são muito sensíveis a preço. Das pequenas empresas não informatizadas, $41 \%$ afirmam que o motivo é não ter condições de investir nesta área, segundo informações da Sondagem Sebrae (1999). Outro grande problema com relação aos custos é a avaliação do preço da nova tecnologia. Os três, segundo Souza Neto (1998), são o custo de desenvolvimento, o preço de mercado e a receita esperada.

O fator tempo é considerado por El-Manaki (1990) como uma das barreiras encontradas pela pequena empresa que dificulta a incorporação de tecnologias informatizadas em seus sistemas administrativos; a outra é o custo. Em virtude do dinamismo da pequena empresa, seu sistema de informação não pode levar muito tempo para ser desenvolvido e implantado. Segundo Penteado (1996), não são apenas as grandes empresas que têm pressa de informatizar seus processos; as pequenas também. 
Satisfeitos os quesitos de custo e tempo, a pequena empresa não pode abrir mão do fator qualidade nos seus sistemas de informação. Se qualidade pode ser definida como adequação ao uso (Paladini, 1997), um sistema de informação deve ser adequado às necessidades da pequena empresa. De acordo com Silva (1997), a informática representa para o pequeno empresário os trinômios bons, simples e baratos; para Paulo Castro da IBM, esta é a linguagem do small business de hoje e do futuro.

Como a pequena empresa não possui hierarquia formal, ela não distingue as necessidades de informação de maneira metódica. Muitas vezes o proprietário/ gerente, além de supervisionar os processos, assume papéis operacionais no diaa-dia da empresa. Dessa forma, o sistema de informação deve possuir características ao mesmo tempo estratégicas, táticas e operacionais, de acordo com Thong (2002).

As necessidades de informação da pequena empresa podem ser exemplificadas com base nas funções gerenciais. Assim, as informações necessárias refletem a urgência com que as decisões devem ser tomadas, em virtude da horizontalização da estrutura hierárquica da empresa. Para o autor informação sobre matéria prima, produtos em processo e/ou acabados e disponibilidade e custo de estoque podem reduzir a pressão e potenciar decisões tomadas no decorrer das atividades do proprietário/gerente da pequena empresa no que diz respeito à produção e materiais. Em recursos humanos, as informações necessárias são os registros de empregados, folha de pagamento, programas de treinamento e férias, disponibilizadas de maneira ágil, possibilitando que o proprietário utilize seu tempo no negócio principal da empresa.

A compilação de dados financeiros requer tempo e análise pelo responsável por esta atividade. Um sistema de informação pode reduzir esse tempo, além de projetar tendências ou simular situações refletidas nas contas a pagar, contas a receber e fluxo de caixa da empresa. Na função de marketing, as informações podem auxiliar análises atuais de vendas, comparar históricos e projetar tendências, tendo em vista a precária dinâmica de fluxo de caixa das pequenas empresas.

\section{Implementação de Tecnologia da Informação na Pequena Empresa}

Para Saviani (1995) a área de informática da pequena empresa não tem visão estratégica da utilização de hardware e software para a produção de informações.

Segundo o autor, isto se dá porque, na maioria das vezes, o 'gerente' dessa área geralmente é um ex-programador. A situação fica mais complexa, ao saber 
que as pequenas empresas brasileiras não desenvolvem um Plano de Metas que as oriente para o futuro de um, dois ou três anos.

Dessa forma, fica cada vez mais difícil que a produção de informações seja o maior objetivo de uma área de informática moderna. Neste sentido, é fundamental o estabelecimento de um Plano Diretor de Informática (PDI), mas somente depois de desenvolvido o Plano de Metas, dentro do qual a informática agiria como apoio do planejamento estratégico da empresa. A estratégia de PDI tem como missão básica o apoio, por meio do processamento eletrônico de dados, de cada segmento do Plano de Metas, produzindo informações gerenciais com qualidade, atendidos os quesitos de custo e prazo, conforme Saviani (1995). Outro ajuste, igualmente necessário, é fazer com que cada usuário de um sistema informatizado entenda seu sistema não apenas de forma isolada e independente, mas de maneira integrada com todas as áreas da empresa.

Uma estratégia para as pequenas empresas, que até o momento não tiveram contato com as novas tecnologias de informação, segundo Yong (1994), foi dividida em duas etapas:

a) Familiarizar-se com a tecnologia de computadores, adquirindo um microcomputador que possa ajudar nas funções não essenciais da empresa.

b) Analisar as metas da empresa e suas esferas essenciais para aplicar tecnologias de informação, nas esferas essenciais dos resultados pretendidos.

Com o tempo, o pequeno empresário terá visão realista da maneira como os dados fluem na sua empresa e idéia aproximada de quais são as prioridades, analisando os impactos dos resultados sobre a produtividade. Não importa qual a tecnologia escolhida: esta deve ser flexível e adaptar-se ao desenvolvimento da organização.

De acordo com o Sebrae (2000), as vantagens que a TI traz para a pequena empresa podem ser dividias em três grupos.

a) Menores custos: a informática, quando bem utilizada, reduz os custos da empresa, porque agiliza e possibilita maior segurança e confiabilidade nos processos, rotinas e controles administrativos; simplifica as tarefas burocráticas; reduz os erros e praticamente elimina a repetição do trabalho.

b) Maior produtividade: possibilita que as pessoas produzam mais, em menos tempo, com menor dispêndio de recursos; permite aproveitar melhor a capacidade produtiva da empresa com o planejamento e o controle da produção; armazena e localiza imediatamente informações fundamentais para os negócios; agiliza os 
processos de tomada de decisões em relação a preços, estoques, compras e vendas, entre outros.

c) Maior qualidade: a qualidade dos produtos e serviços é melhorada, pois as tecnologias de informação ajudam a manter o padrão dos produtos dentro das especificações estabelecidas; proporciona melhores condições de trabalho para os empregados; reduz esforços com a burocracia para concentrá-los nas atividades fins da empresa.

\section{Metodologia}

Esta pesquisa destaca-se por constituir-se num multicaso, no qual a amostra foi intencional; haja vista a dificuldade na obtenção de retorno das empresas, quando escolhidas por meio de um plano amostral aleatório (Kerlinger, 1980).

O estudo ocorreu em níveis exploratórios, contando com a participação de 25 empresas dos setores eletro-eletrônico, distribuição e comércio e serviços da macrorregião de Ribeirão Preto-SP, no primeiro trimestre de 2002. Os dados primários e secundários foram coletados; utilizou-se como instrumento de pesquisa um questionário, sendo analisados por meio de estatística descritiva e análise documental, respectivamente.

O instrumento de pesquisa foi construído em três partes: (1) perfil empresas; (2) utilização da TI; e (3) características dos impactos causados pela TI. As perguntas foram respondidas na escala de Likert, variando de 1 a 5; sendo $1=$ nenhuma, 2= baixa, 3 = média, 4= elevada, 5= total, calculando-se as médias e desvio-padrão.

\section{Estudo do Impacto da Introdução de Tecnologia da Informação em Pequenas Empresas}

As empresas pesquisadas integram os setores eletro-eletrônico (35\%), comércio e serviços (42\%), distribuição (10\%) e varejo (13\%). Dentre as empresas pesquisadas, em 55\% a TI já foi implantada há mais de 10 anos e em 7 \% há mais de 7 anos, evidenciando que o uso de TI já se tornou uma realidade nas empresas de pequeno porte. 
Dentre as empresas pesquisadas, $23 \%$ possuem até 10 funcionários; $55 \%$ possuem entre 11 e 25 funcionários; e 22 \% entre 26 e 99 funcionários.

Em referência à diferenciação vertical, percebeu-se que a maioria das organizações pesquisadas possui estrutura organizacional reduzida em termos de níveis hierárquicos: dois níveis (59\%); três níveis (28 \%); e quatro níveis (13\%). Isto indica a adoção de uma estrutura horizontalizada que fornece maior rapidez na tomada de decisão, além de comunicação mais rápida e eficiente.

Na maioria das empresas, a adoção da TI surge em função de uma necessidade derivada dos objetivos organizacionais preestabelecidos. Assim, um dos itens avaliados refere-se à identificação dos motivos que levaram as empresas a implantar a TI. Os motivos considerados mais importantes são apresentados na Tabela 1 abaixo.

Tabela 1: Motivos para Implantação de TI

\begin{tabular}{|l|l|}
\hline Motivos para implantação de TI & $\%$ \\
\hline Necessidade de integração & 2 \\
\hline Melhoria de controles organizacionais & 24 \\
\hline Competitividade & 8 \\
\hline Manter sua participação & 5 \\
\hline Aumentar sua participação & 22 \\
\hline Melhoria da qualidade de atendimento & 8 \\
\hline Aumentar a produtividade & 20 \\
\hline Gerar um ambiente criativo & 1 \\
\hline Reduzir custos & 10 \\
\hline
\end{tabular}

A seguir é demonstrada a amplitude do uso da TI, por meio da identificação do estágio, conforme as estratégias de negocio de cada uma, além da porcentagem de cada tipo de Sistema de Informação utilizado pela empresa. Na Tabela 2, encontra-se a descrição do estágio segundo Nolan (1977).

Salienta-se que as empresas se concentram nos estágios iniciais da implantação de TI, sendo que 43,1 \% das empresas estão no estagio 1 (Iniciação), 29,1 \% no Contágio. 


\section{Tabela 2: Amplitude do Uso da TI por Parte das Empresas Estudadas}

\begin{tabular}{|l|l|l|l|l|l|l|l|}
\hline Estágios & $\begin{array}{l}2 \\
(\%)\end{array}$ & $\begin{array}{l}(\%) \\
(\%)\end{array}$ & $\begin{array}{l}3 \%) \\
(\%)\end{array}$ & $\begin{array}{l}5 \\
(\% \text { Média }\end{array}$ & $\begin{array}{l}\text { Desvio. } \\
\text { Padrão }\end{array}$ \\
\hline Iniciação & 15,2 & 2,5 & 43,1 & 25,2 & 19,8 & 3,58 & 1,28 \\
\hline Contagio & 15,3 & 29,1 & 15,3 & 15,2 & 25,2 & 3,06 & 1,42 \\
\hline Controle & 25,2 & 9,00 & 25,2 & 15,2 & 25,2 & 3,05 & 1,57 \\
\hline Integração & 15,2 & 15,2 & 39,2 & 15,2 & 15,2 & 3,01 & 1,19 \\
\hline Administração de dados & 25,2 & 25,2 & 25,2 & 4,40 & 20,0 & 2,68 & 1,41 \\
\hline Maturidade & 57,1 & - & 25,2 & 7,10 & 10,6 & 2,15 & 1,48 \\
\hline
\end{tabular}

Escala Utilizada: 1= Nenhuma, 2= Baixa, 3 = Média, 4= Elevada, 5=Total.

Em toda a introdução de tecnologia ocorrem obstáculos, internos e externos, como resistências para os internos e mudança de cenário financeiro para os externos. Em relação à implantação da TI nas pequenas empresas estudadas, as principais barreiras enfrentadas são descritas na Tabela 3.

Os resultados indicam que as dificuldades foram percebidas como muito expressivas, sendo a resistência por parte dos funcionários sem conhecimento prévio de informática a mais relevante, pois estes temiam serem substituídos por computadores.

\section{Tabela 3: Dificuldades Encontradas na Implantação da TI}

\begin{tabular}{|l|l|l|l|l|l|l|l|}
\hline Dificuldades encontradas & $\begin{array}{l}1 \\
(\%)\end{array}$ & $\begin{array}{l}2 \\
(\%)\end{array}$ & $\begin{array}{l}3 \\
(\%)\end{array}$ & $\begin{array}{l}4 \\
(\%)\end{array}$ & $\begin{array}{l}5 \\
(\%)\end{array}$ & Média & $\begin{array}{l}\text { Desvio } \\
\text { padrão }\end{array}$ \\
\hline Resistência pelos funcionários & 20 & 05 & 35 & 20 & 20 & 3,20 & 1,47 \\
\hline Cultura tradicional & 10 & 10 & 50 & 30 & - & 3,01 & 1,24 \\
\hline Ausência de pessoal qualificado & 40 & 05 & 40 & 15 & - & 2,75 & 1,19 \\
\hline Falta de suporte técnico & 38 & - & 38 & 26 & - & 2,56 & 1,17 \\
\hline Falta de sinergia entre as áreas & 40 & - & 40 & 20 & - & 2,41 & 1,17 \\
\hline $\begin{array}{l}\text { Apreensão os funcionários pela falta de } \\
\text { reinamento }\end{array}$ & 43 & - & 43 & 14 & - & 2,38 & 1,14 \\
\hline Dificuldades internas & 35 & - & 35 & 25 & 05 & 2,15 & 1,11 \\
\hline Falta de clareza estratégica & 40 & 20 & 40 & - & - & 2,09 & 1,08 \\
\hline Falta de recursos financeiros & 40 & 20 & 40 & - & - & 1,95 & 1,01 \\
\hline Erro na implantação & 75 & - & 15 & - & 10 & 1,90 & 1,00 \\
\hline Equipamentos obsoletos & 60 & - & 40 & - & - & 1,80 & 0,98 \\
\hline Clima motivacional desfavorável & 60 & 20 & 20 & - & - & 1,70 & 0,95 \\
\hline Falhas na segurança & 70 & - & 30 & - & - & 1,60 & 0,89 \\
\hline $\begin{array}{l}\text { Necessidade de mudança na estrutura } \\
\text { organizacional }\end{array}$ & 85 & - & 15 & - & - & 1,31 & 0,86 \\
\hline Ergonomia & & & & & & & \\
\hline Problemas de apoio da alta gerência & 86 & - & 14 & - & - & 1,22 & 0,81 \\
\hline
\end{tabular}

Escala utilizada: 1= Nenhuma, 2= Baixa, 3= Média, 4= Elevada, 5=Total. 
Para a obtenção de êxito no uso da TI é imprescindível que alguns fatores organizacionais de ordem técnica, social e financeira estejam alinhados para fornecer infra-estrutura adequada, como pode ser observada na Tabela 4 a seguir.

Entre os fatores mais importantes para o êxito da TI em pequenas empresas nota-se a percepção da necessidade do uso da TI pelos usuários, apoio da cúpula executiva e treinamento para os usuários.

Entretanto a responsabilidade do gerente de operações, dedicação da equipe de implementação e superação das barreiras socioculturais são consideradas de média e elevada importância.

\section{Tabela 4: Fatores de Êxito para Utilização de TI}

\begin{tabular}{|l|l|l|l|l|l|l|l|}
\hline Fatores de Êxito & $\begin{array}{l}1 \\
(\%)\end{array}$ & $\begin{array}{l}2 \\
(\%)\end{array}$ & $\begin{array}{l}3 \\
(\%)\end{array}$ & $\begin{array}{l}4 \\
(\%)\end{array}$ & $\begin{array}{l}5 \\
(\%)\end{array}$ & Média & $\begin{array}{l}\text { Desvio } \\
\text { padrão }\end{array}$ \\
\hline Percepção da necessidade pelos usuários & - & - & 41,6 & 29,2 & 29,2 & 3,72 & 0,90 \\
\hline Apoio da cúpula executiva & 14,6 & 14,6 & 41,6 & 29,2 & - & 3,70 & 1,05 \\
\hline Treinamento adequado & - & 29,2 & 41,6 & 29,2 & - & 3,65 & 1,40 \\
\hline Aceitação por toda a organização & 14,6 & 41,6 & 14,6 & 14,6 & 14,6 & 2,75 & 1,25 \\
\hline Dedicação da equipe de implementação & - & 14,6 & 58,8 & 14,6 & 14,6 & 2,70 & 1,20 \\
\hline Responsabilidade do gerente de operações & 14,6 & 85,4 & - & - & - & 2,45 & 0,85 \\
\hline Superação de barreiras sócio-culturais & 29,2 & 56,5 & 14,3 & - & - & 2,12 & 0,96 \\
\hline
\end{tabular}

Escala utilizada: 1= Nenhuma, 2= Baixa, 3= Média, 4= Elevada, 5=Total.

Na Tabela 5, as vantagens proporcionadas pela introdução de TI em empresas foram agrupadas de acordo com Zuboff (1994), considerando suas similaridades, visando a facilitar a compreensão dos resultados alcançados.

Analisando-se os benefícios referentes ao Aumento de continuidade, verificase que não houve tendência generalizada de grandes benefícios alcançados pelas empresas nesse quesito. Percebe-se que um número relativamente pequeno de empresas obteve vantagens elevadas e totais, advindas da implantação de TI, exceto as facilidades conferidas pelo aumento da velocidade de resposta, diretamente proporcional à velocidade e acompanhamento da capacidade de processamento dos hardwares comprados pela empresa.

Para o conjunto de benefícios relacionados à Melhoria nos controles, esses estão evidenciadas na redução das redundâncias de operações e relatórios mais consistentes. Visto que todos esses fatores obtiveram avaliações próximas ou superiores à importância elevada. Essas vantagens foram obtidas graças à menor repetição do trabalho de digitação, busca por informações que já estão incluídas em banco de dados como de clientes, fornecedores e de modelos de documentos já formatados; relatórios mais consistentes devem-se ao fato de que os sistemas 
de informação poder consolidar informações de várias operações que compõem as funções gerenciais como vendas, finanças, recursos humanos e outras.

Com relação às vantagens de Melhoria de compreensão das funções produtivas, pode ser verificada uma melhoria acentuada no aumento de satisfação dos usuários, o que ocorre devido à sensação do aumento na capacidade de executar tarefas com mais eficiência e eficácia e seguida por melhoria no processo de planejamento e direção na organização e aumento na capacidade de correlação entre as diversas áreas da empresa. Por meio de sistemas de informação, os diretores e gerentes podem visualizar a empresa e suas áreas como um todo, ao longo do processo produtivo, determinando as áreas deficientes.

\section{Tabela 5: Benefícios Obtidos pela TI em Pequenas Empresas Estudadas}

\begin{tabular}{|c|c|c|c|c|c|c|c|}
\hline Benefícios & \begin{tabular}{|l|l|}
1 \\
$(\%)$
\end{tabular} & \begin{tabular}{|l|}
2 \\
$(\%)$
\end{tabular} & \begin{tabular}{|l|l|}
3 \\
$(\%)$
\end{tabular} & $\begin{array}{l}4 \\
(\%)\end{array}$ & $\begin{array}{l}5 \\
(\%)\end{array}$ & Média & $\begin{array}{l}\text { Desvio } \\
\text { padrão }\end{array}$ \\
\hline \multicolumn{8}{|l|}{ Aumento de continuidade } \\
\hline Facilita a integração funcional & 15 & 45 & 15 & 18 & 12 & 2,82 & 1,06 \\
\hline Aumento da automação operacional & 12 & 48 & 20 & 10 & 10 & 2,58 & 1,19 \\
\hline Aumento da velocidade de resposta & 15 & 10 & 20 & 45 & 20 & 4,65 & 1,30 \\
\hline Melhoria do fluxo de trabalho & 15 & 40 & 15 & 15 & 15 & 2,75 & 1,35 \\
\hline \multicolumn{8}{|l|}{ Melhoria nos controles } \\
\hline Redução de custos operacionais & 18 & 35 & 21 & 12 & 14 & 2,71 & 1,41 \\
\hline Melhoria na precisão de entrada de dados & 19 & 41 & 20 & 12 & 08 & 2,49 & 1,60 \\
\hline Melhoria na acuidade de saída de relatórios & 14 & 41 & 15 & 12 & 18 & 2,85 & 1,25 \\
\hline Redução de redundância de operações & 07 & 10 & 10 & 48 & 25 & 4,18 & 1,85 \\
\hline Aumento na previsibilidade de cenários & 18 & 36 & 22 & 12 & 12 & 2,64 & 1,69 \\
\hline Relatórios mais consistentes & 10 & 04 & 34 & 20 & 32 & 3,81 & 1,54 \\
\hline Menor risco na tomada de decisão & 25 & 40 & 15 & 10 & 10 & 2,43 & 1,56 \\
\hline \multicolumn{8}{|l|}{ Melhoria de compreensão das funções produtivas } \\
\hline $\begin{array}{l}\text { Melhoria no processo de planejamento e direção na } \\
\text { organização }\end{array}$ & 15 & 25 & 40 & 20 & 20 & 3,65 & 1,12 \\
\hline Aumento de satisfação dos usuários & 08 & 07 & 05 & 15 & 65 & 4,85 & 0,98 \\
\hline Melhoria na capacidade de visão total do negocio & 13 & 27 & 40 & 10 & 10 & 2,77 & 0,99 \\
\hline $\begin{array}{l}\text { Melhoria na capacidade de auto-avaliação da } \\
\text { qualidade de serviço }\end{array}$ & 12 & 20 & 30 & 28 & 10 & 3,04 & 1,02 \\
\hline $\begin{array}{l}\text { Aumento na capacidade de correlação entre as } \\
\text { diversas áreas da empresa }\end{array}$ & 06 & 14 & 30 & 33 & 17 & 3,41 & 1,27 \\
\hline
\end{tabular}

Escala utilizada: 1= Nenhuma, 2= Baixa, 3= Média, 4= Elevada, 5=Total.

\section{Considerações Finais}

Este estudo analisou as características de vinte e cinco pequenas empresas da macrorregião de Ribeirão Preto -SP, nos setores eletro-eletrônico, serviços, 
transporte e varejo. Essas empresas, em sua maior parte, possuem estrutura organizacional enxuta de até quatro níveis, sendo que a maioria possui dois níveis (59\%), no que se refere ao grau de hierarquização. Destaca-se que a TI vem sendo utilizada pelas organizações por mais de dois anos em 82 \% delas, e constitui para elas ferramenta estratégica no processo de planejamento, direção e controle.

A maior dificuldade encontrada na sua utilização está relacionada à resistência por parte dos funcionários, indicando falta de treinamento e explicação prévia à implantação dos benefícios que seriam trazidos nas atividades rotineiras, levando tais funcionários a pensar que poderiam perder seus postos de trabalho para a TI. Além disso, havia a cultura tradicional da empresa em realizar suas tarefas; logicamente a mudança implicava o temor e a percepção de que ocorreriam alterações no modo operacional.

É importante considerar que, na presente pesquisa, os dois fatores de êxito mais altos, apontados pelas empresas, foram a percepção da necessidade pelos usuários e o apoio da cúpula administrativa. Mesmo tendo ocorrido a resistência, os resistentes, após a implantação da TI, perceberam a sua importância nos processos, aumentando a capacidade de trabalho, levando a empresa a robustecer a sua competitividade. O mesmo pode-se se dizer da cúpula administrativa; apesar de a maioria das empresas pequenas ainda considerar a TI como custo e não como vantagem competitiva, essas foram capazes de apoiar a implantação da TI, percebendo que não haveria outra maneira de permanecer no negócio a não ser melhorar seus controles gerenciais e aumentar a produtividade.

Por fim, destaca-se que as empresas estão visualizando como a TI pode ser útil, porém não conseguiram ainda avaliar, em termos de custo/benefício, o investimento realizado. Os benefícios com maior intensidade, por outro lado, estão relacionados à melhoria de compreensão das funções produtivas, principalmente ao aumento da satisfação do usuário, em melhoria de controles (redução de redundância de operações e aumento de continuidade), em face da maior velocidade de resposta.

Fator limitante do trabalho foi o número reduzido de empresas no estudo, uma vez que muitas empresas se mostraram relutantes em responder às questões retratadas na pesquisa, justificando que o tema era de natureza estratégica para seus negócios.

Em futuras pesquisas, deverão ser desenvolvidos estudos quantitativos e qualitativos, para se identificarem e compararem os resultados da implantação da TI em empresas de diferentes localizações: ambiente urbano e rural, nível intelectual do proprietário, além de outras variáveis.

Artigo recebido em 22.04.2003. Aprovado em 26.12.2003. 


\section{Referências Bibliográficas}

\author{
ANANDARAJAN, M; \\ IGBARIA, M.; \\ ANAKWE, U. P.
}

It acceptance in a less developed country: a motivational factor perspective. International Journal of Information Management, n.22, p.4765, 2002.

ATTEWELL, L. P.

Technological diffusion and organizational learning: the case of business computing. Organization Science, v. 3, n.1, p.1-19, 1992.

CHAVES, E. O. C.;

FALSARELLA,O. M.

Os sistemas de informação e sistemas de apoio à decisão. Revista do Instituto de Informática, v. 3, n.1, p. 24-31, 1995.

EL-NAMAKI, M. S. S.

Small Business: the myths and the reality. Long Range Planning, v.23, n.4, p.78-87,1990.

\section{FULLER, T.}

Fullfilling IT needs in small businesses: a recursive learning model. International Small Business Journal, v.14, n.4, p-25-44,1996.

GIURLIANI, S.

A difícil arte de fazer contas. Gestão Empresarial,v.1, n. 3, p.7-16, 1999.

GONÇALVES, J. E. L.

Os impactos das novas tecnologias nas empresas prestadoras de serviço. Revista Administração de Empresas, v. 34, n. 1, p.63-81, 1993.
KERLINGER, F. N.

Metodologia da Pesquisa em Ciências Sociais. São Paulo: EPU, 1980.

\section{MACHADO, C.}

Como dar o tiro certo na hora de decidir. Informática Exame. São Paulo: Editora Abril, v.11, n.120, p.4955, 1996.

\section{NOLAN, A.}

Information Systems. New York: HTE, 1977.

OLIVEIRA, A. C.

Tecnologia de informação: competitividade e políticas públicas. Revista de Administração de Empresas, v. 36, n. 2, p. 34-43, 1996.

\section{PALADINI, E. P.}

Gestão da Qualidade no Processo: a Qualidade na Produção de Bens e Serviços. São Paulo: Atlas, 1995.

PALVIA, P. C.;

PALVIA, S. C.

An examination of the IT satisfaction of small business users. Information \& Management, v. 5, n.35, p.127-137, 1999.

PENTEADO, S.

Chegou a vez das pequenas. Informática Exame, São Paulo: Editora Abril, v.11, n.119, p.52-57, 1996. 
SAVIANI, J. R.

Repensando as pequenas e médias empresas: como adequar os processos de administração aos novos conceitos de modernidade. São Paulo: Makron Books, 1995.

\section{SEBRAE}

Informática: solução para a pequena empresa. Brasília: SEBRAE, 1994.

\section{SILVA, V.L.}

O grande salto das pequenas. Pequenas empresas, grandes negócios, São Paulo: Editora Globo, v.IX, n.104, p.86-88, 1997.

\section{SOLOMON, S.}

A grande importância da pequena empresa: a pequena empresa nos Estados Unidos no Brasil e no mundo. Rio de Janeiro: Editorial Nórdica, 1986.

\section{SONDAGEMCONJUNTURAL}

Comércio varejista. Rio de Janeiro: FGV/SEBRAE, v.8, n.46, 2000.

\section{SONDAGEM SEBRAE}

$2^{a}$ Pesquisa sobre informatização e impacto do “Bug do Milênio". Brasília: SEBRAE, v.8, n.44, 1999.

\section{SOUZA NETO, J.A.}

Negociação de tecnologia. Porto Alegre: SEBRAE, 1998.

\section{SILVA, A.}

Globalização, tecnologia e informação: a tríade que desafia a administração. Revista Brasileira de Administração, v. VIII, n. 22, p.10-19, 1998.
STONER, J.A. F.

Administração. 5. ed. Rio de Janeiro: LTC, 1999.

TAURION, C.

A bula para combater custos. Gestão Empresarial, São Paulo: IDS, ano I, n. 3, p.18-20, 1999.

TEIXEIRA, C. Z.

Organização industrial da pequena empresa. São Paulo: IBRASA, 1986.

THONG, J. Y. L.

Resource constraints and information systems implementation in Singaporean small businesses. Omega, n.29, p.143-156, 2001.

\section{WELSH, J.;}

WHITE, J. F.

A small business is not a little big business. Harvard Business Review, v.59, n.4, p. 18-32, 1981.

YONG, C.S.

Tecnologia de informação. Revista de Administração de Empresas, v. 32, n.1, p.78-87, 1992.

\section{ZUBOFF, S.}

Automatizar/informatizar as duas faces da tecnologia inteligente. Revista de Administração de Empresas, v. 34, n. 6, p. 80-91, 1994. 